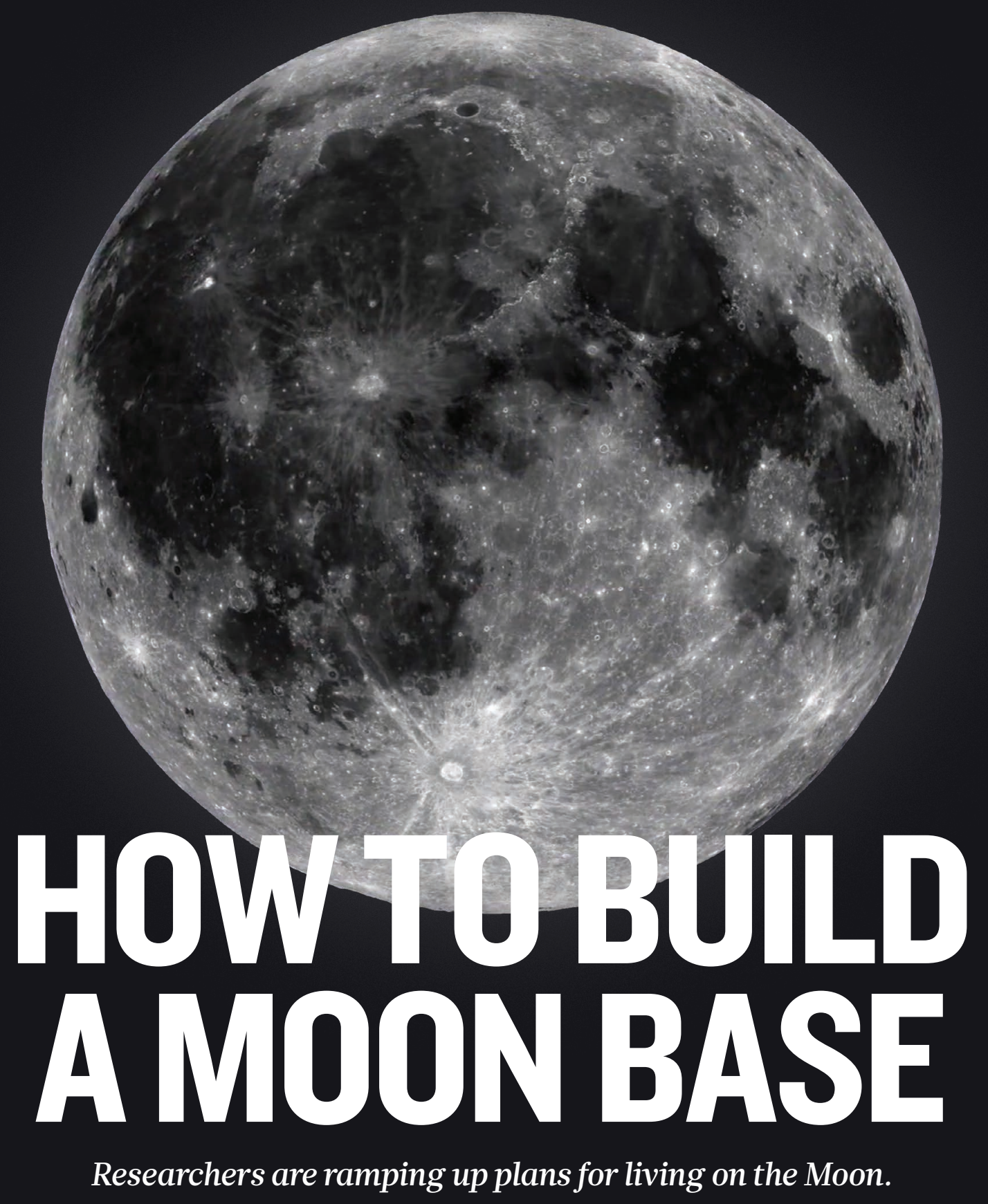

BY ELIZABETH GIBNEY

$\mathrm{N}$ ext year, astronaut Matthias Maurer expects to walk on the surface of the Moon - but without the hassles of a rocket flight, zero-gravity nausea and a risky landing. Instead he'll stroll close to home in a leafy meadow near Cologne, Germany, which is set to host the largest Moon mock-up ever made. On a pit of artificial lunar dust covering more than 1,000 square metres, Maurer and other scientists will be attached to crane-and-pulley systems that allow them to leap as if experiencing the Moon's weaker gravity, and work under adjustable lamps that simulate lighting at different lunar sites. Sometimes, they will retreat to lunar-style living quarters: an airlock-connected module the size of a shipping container.

It's an exciting playground for testing lunar technology, says Maurer, who is a project manager for the multimillion-euro facility. Called LUNA, the mock-up is taking shape outside the European Astronaut Centre in Cologne, with funding from the European Space Agency
(ESA) and the German Aerospace Center (DLR). But at 48 years old, Maurer doesn't know whether he will ever put his skills to use on the genuine article. "Hopefully I will make it before retirement. Technically, I believe it's feasible that I will still walk on the Moon," he says.

Maurer's optimism isn't entirely outlandish. He was only two the last time someone visited the Moon for real: US astronaut Eugene Cernan, in the last mission of NASA's Apollo programme. No space agencies have yet committed money to send people back. But, partly as a result of changing political priorities, momentum for human return to the Moon is growing. Rather than rerun the Apollo missions, space agencies $\frac{\pi}{z}$ are slowly warming to the idea of establishing a sustainable settlement.

Researchers relish the idea of a base for conducting experiments on the Moon and as a way to trial technologies for heading to Mars. Private firms, however, are increasingly tempted by the possibility of mining oxygen and hydrogen - which power rockets - from lunar ice. If that 
does pan out, then the Moon could become a refuelling station, radically reducing the expense of space travel. "Water is the oil of space, and there's mounting evidence that it's there in economically viable deposits," says George Sowers, an aeronautical scientist at the Colorado School of Mines in Golden and previously chief scientist at United Launch Alliance, a firm in Centennial, Colorado, that provides launch services for the US government.

Space agencies are generally reluctant to predict a timeline for a crewed Moon base - in part, because the goal lies well outside their budget horizons, but also because it requires businesses to provide much of the money for the various stages involved. But ESA's director-general, Jan Wörner, has for years talked about multiple countries and companies collaborating in a semi-permanent settlement, which he calls a 'Moon village'. China's National Space Administration has also been quoted in state media saying that a Moon base is its goal, although it has not announced when that might happen.

Lunar exploration prospects gained a boost last December, when a US presidential directive told NASA to switch its sights from exploring asteroids to returning humans to the Moon. NASA has since asked companies to develop lander technology and has outlined plans to request billions of dollars over the next five years for new programmes to support lunar exploration, leading to eventual human return. "It's a fairly radical change of direction," says Sowers. And this October, European engineering firm Airbus launched a contest called the Moon Race, with supporters that include ESA and the US spaceflight firm Blue Origin, which promises to fund companies to develop key technologies for the sustainable development of the Moon.

In the next few years, the only missions to touch down on the Moon will be robotic: China and India will launch probes in the next three months, and Russia has one scheduled within the next five years. But NASA, ESA and the space agencies of Russia, Japan and Canada all support the idea of building a space station in orbit around the Moon by the mid-2020s. (In his 2019 budget request, US President Trump proposed that NASA spend US $\$ 2.7$ billion on the project over the next 5 years.) That orbiter could provide a base from which to make short, multiweek crewed trips to the Moon's surface in a pressurized rover - which Maurer calls the "camper-van solution". Finally, a settlement could follow. "I think that 20 years is a realistic time frame for a lunar surface infrastructure of some sort, either inhabited by or tended by humans," says James Carpenter, strategy officer for human and robotic exploration at ESA in Noordwijk, the Netherlands.

Researchers have long explored ways to harvest lunar resources, but more in hope than expectation. Now, they are ramping up lunar settlement technology with genuine anticipation that their work might be put into action. While Maurer and others at ESA's LUNA centre practise living on and mining the Moon, others are working on how to grow food and build radiation-proof shelters (see 'Living on the Moon'). At a July meeting at ESA's European Space Research and Technology Centre in Noordwijk to prepare for future human Moon missions, more than 250 specialists from academia, mining, metallurgy, construction and architecture pitched their ideas. "If you ran the same workshop five years ago, it may have only been a handful of people," says Aidan Cowley, science adviser at the European Astronaut Centre. "The appetite has really increased." Although a Moon base might still never happen, Earthbound preparation for lunar living is well under way.

\section{WATER MINING}

Lunar settlers' first challenge will be harvesting water. The Apollo missions, which collected samples from the Moon's equator, suggested that the satellite is dry and barren. So the discovery a decade ago that the Moon's poles harbour patches of water ice "was a game changer", says
Robert Mueller, a senior technologist at the NASA Kennedy Space Center in Cape Canaveral, Florida, who develops lunar-mining technologies.

For now, researchers don't exactly know where the ice is, how thick it is or whether it is mixed with soil or packed in sheets. India's Chandrayaan-2 rover, scheduled to launch next year, and Russia's LUNA 27 lander, planned for 2022, will target these questions. Russia's lander will have a 2-metre-long drill designed by ESA, and a laboratory to study the origin and abundance of lunar water. NASA also wants to hunt for that water, and has commissioned a suite of companies to develop lunar landers that would carry prospecting instruments, beginning as early as next year. A four-crew human base would need a negligible amount of this water - perhaps dozens of tonnes per year, says Sowers - and there's plenty of it. "Estimates based on current data suggest there may be 10 billion tonnes per pole," he says.

The vast majority of the ice would be mined for fuel. Sowers calculates that mining firms could turn a profit by extracting around 1,000 tonnes of water a year and electrolysing it into its constituent oxygen and hydrogen parts for propellant. The Moon's low gravity means that it would be much cheaper to stock up for long-distance space travel from there than it is from Earth. As an example, a lunar return mission that refuelled at the Moon would cost just one-fiftieth of the price of one that brings all its fuel with it from Earth.

In August, scientists using data from India's Chandrayaan-1 orbiter found that the Moon's ice lies on its surface - but in permanently shaded craters as frigid as $-249^{\circ} \mathrm{C}$, the naturally coldest spots known in the Solar System. Excavation machines would need heat and power to release the water and turn it into propellant. Because plutonium-based batteries, which rely on the heat generated by the natural decay of radioisotopes, are too expensive for most private firms, lunar prospectors will probably have to harness energy from the Sun.

They will take inspiration from southern Norway, where giant mirrors set high on a mountain overlooking the town of Rjukan have since 2013 beamed sunlight onto a patch of the town's central square that would otherwise be grey and chilly all winter. Prospectors would hope to do something similar on the Moon, says Sowers. Light from high peaks could be directly channelled into the craters, he says, where it would heat the ice and turn it into vapour. From there, condensed water would be shuttled to a processing plant and split by solar electricity into hydrogen and oxygen. These gases could then be stored and either used as propellant or channelled through fuel cells to supply energy.

Alternatively, rovers could scoop up ice-filled soil and warm it in ovens to release water. The ovens could be powered wirelessly, by training highpower lasers onto photovoltaic cells on the rover. The LUNA facility could test how this would work in real life, with added challenges such as Moon dust in the atmosphere that scatters the laser beams, says ESA's Leopold Summerer. LUNA scientists will also clamber into life-like Moon craters to see how easy it is to navigate these deep, dark slopes, Maurer says.

\section{LIVING OFF THE SOIL}

If ice isn't accessible, there is an alternative source of water on the Moon: its soil, also known as regolith. Regolith contains silica and metallic oxides that make it - on average - $43 \%$ oxygen by mass, and it is found everywhere on the Moon. Oxygen grabbed from soil could power scientifically or economically interesting outposts far from the poles, and produce useful by-products such as rare metals.

Regolith doesn't give up its riches easily. Releasing oxygen from its chemical bonds is more energy-intensive than heating ice. In theory, a reactor could use giant mirrors to channel sunlight onto a furnace little bigger than an envelope, heating Moon dirt to more than $900^{\circ} \mathrm{C}$ until it glows. At that temperature, hydrogen or carbon, brought initially from Earth, can strip oxygen from its minerals and bind the element together 
UNAR ORBITAL

\section{PLATFORM}

Humanity's next international outpost in space might be a lunar orbiter, after the International Space Station is retired, probably in the mid-2020s. Supported by NASA, ESA, JAXA and others, this hub could launch rovers to the Moon and act as staging post for humans travelling to the lunar surface.
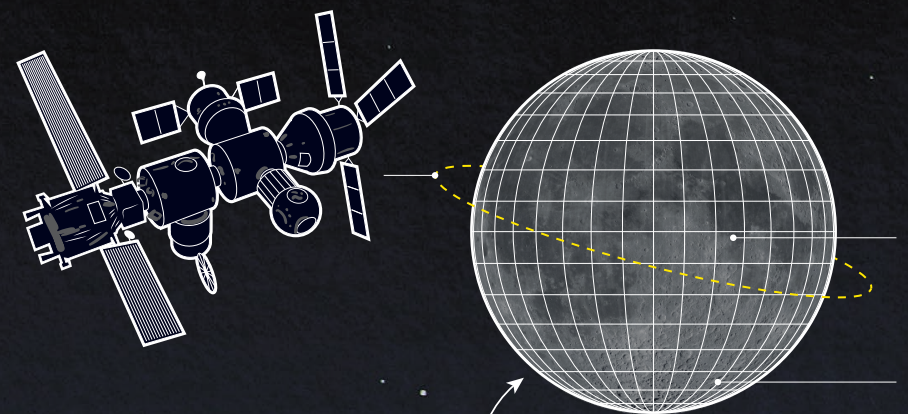

WHERE TO SETTLE

EQUATOR

$A$ base on the equator would be the easiest site to land and launch from, and would be in constant communication with Earth. But lunar nights- would prove a challenge for power.

POLES

A settlement in the polar regions offers access

to icy deposits for mining, interesting geology

and sunlit uplands, but shadowed terrain

makes landing difficult, and Earth

\section{be installed on the far side of the Moon,}

$\begin{aligned} & \text { Scientists hope that a telescope might } \\ & \text { be installed on the far side of the Moon, } \\ & \text { where sensitive radio receivers would be } \\ & \text { shielded from interference from Earth. }\end{aligned}$

\section{FAR-SIDE TELESCOPE}

Scientists hope that a telescope might
POWER

Photovoltaic arrays could generate electricity, with solar concentrators providing heat for beam energy from sunlit areas to shadowed regions. Solar-driven electrolysers could split water into oxygen and hydrogen, which can form propellant or be recombined in fuel
cells for energy at night.

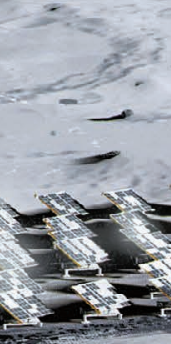
HIVIN ON
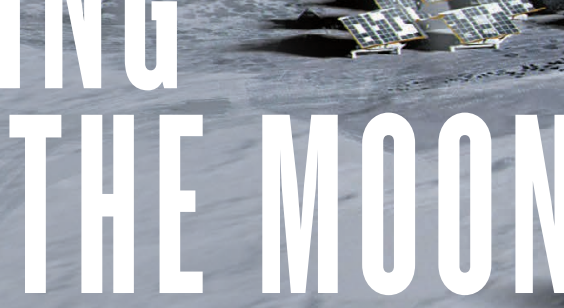

HOW WE MIGHT RETURN TO THE MOON - AND SET UP CAMP THERE.

BY ELIZABETH GIBNEY

ILLUSTRATION BY MACIEJ RĘBISZ

DESIGN BY JASIEK KRZYSZTOFIAK

No one has committed money to send humans back to the Moon. But momentum is building for a lunar return. And scientists are already preparing technologies for a sustainable settlement on Earth's satellite that could generate fuel, water, food and shelter to support a human base and act as a refuelling station for missions farther afield. Here's what it might look like.

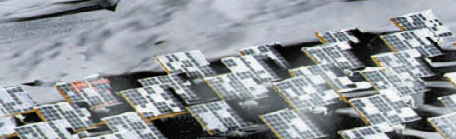

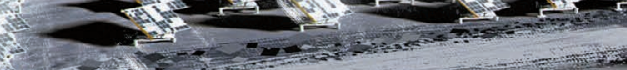
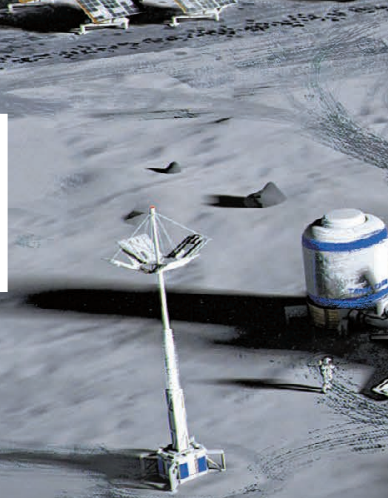

Solarpanels
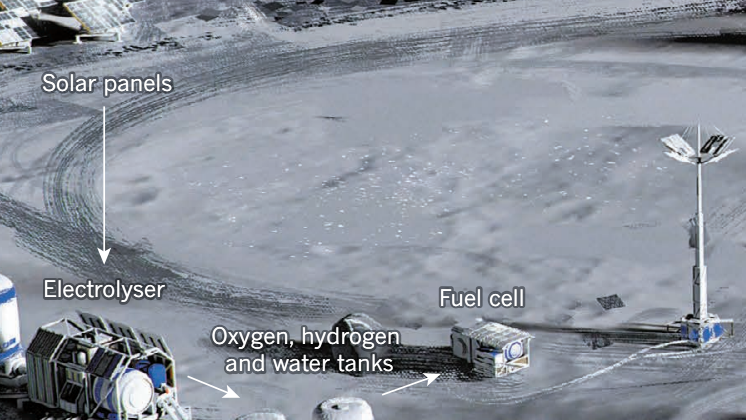
$>$
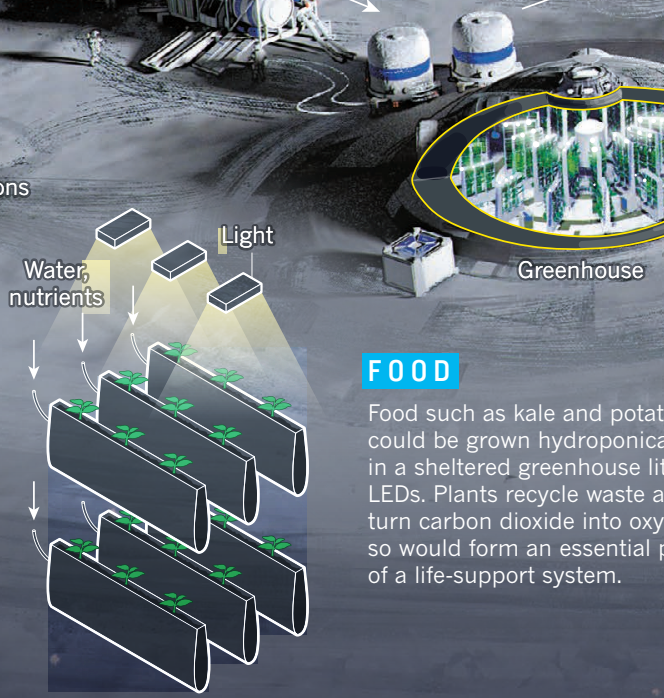

F OOD

Food such as kale and potatoes could be grown hydroponically in a sheltered greenhouse lit by LEDs. Plants recycle waste and turn carbon dioxide into oxygen, so would form an essential part of a life-support system.

\section{WHEN? - Scheduled Expected o Speculative}

\begin{tabular}{|c|c|c|c|}
\hline $\begin{array}{l}18-19 \\
\text { ina and India launch }\end{array}$ & $\begin{array}{l}2020 \\
\text { First }\end{array}$ & $\begin{array}{l}2022-23 \\
\text { Russia's LUNA }\end{array}$ & $\begin{array}{l}2025 \\
\text { ESA mission to }\end{array}$ \\
\hline $\begin{array}{l}\text { Ina missions to lunar } \\
\text { ar side and far side. }\end{array}$ & $\begin{array}{l}\text { commercial } \\
\text { lunar landers }\end{array}$ & $\begin{array}{l}\text { lander heads to } \\
\text { a polar region. }\end{array}$ & $\begin{array}{l}\text { mission to } \\
\text { instrate water or } \\
\text { n harvesting. }\end{array}$ \\
\hline
\end{tabular}

Late 2020s

Short-stay human missions to the Moon in pressurized rover. Tests of near side and far side. lunar landers. a polar region.

\section{$2018 \quad 2020$ \\ 2020}

Launch of NASA's

heavy-lifting Space Launch System and Orion craft.

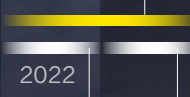

2022 Construction starts on outpost n lunar orbit.

$20232024 \quad$ Mid-late 2020s

NASA's first crewed First crew

trip around the Moon inhabits orbiting in half a century.

lunar outpost.
Robotic scouts

prepare for human exploration. \begin{tabular}{l|l}
2030 & 2032
\end{tabular}

From 2030s

First habitats with

support systems and use of lunar resources.
2034

\section{ate 2030s}

Semi-permanent lunar settlement 


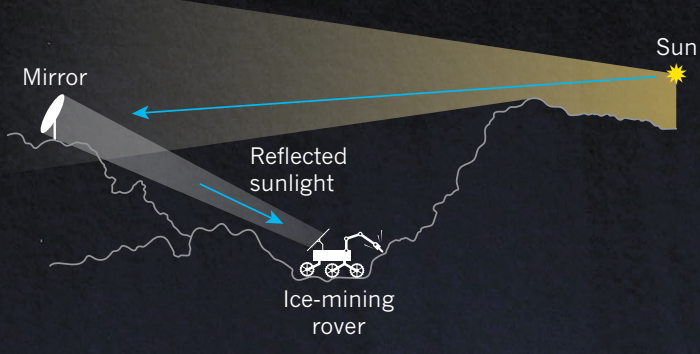

\section{ICE}

Surface ice - in permanently

shadowed craters - would be

the readiest source of oxygen

and hydrogen. Sunlight,

channelled into the craters with

mirrors, could heat the ice, and

an overhead dome could

capture water vapour. Or rovers

could be equipped with ovens

that would warm ice-filled soil to make water.
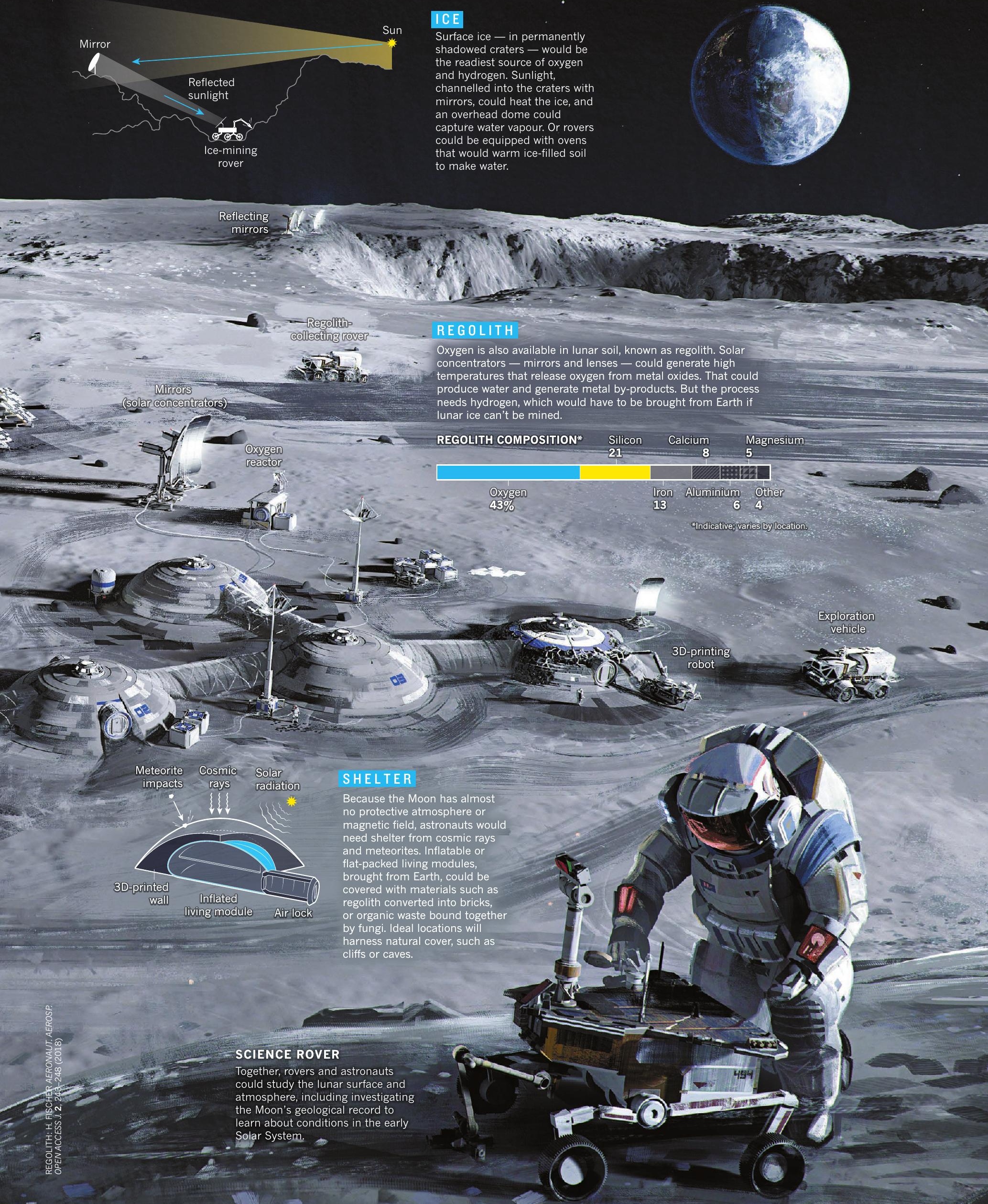


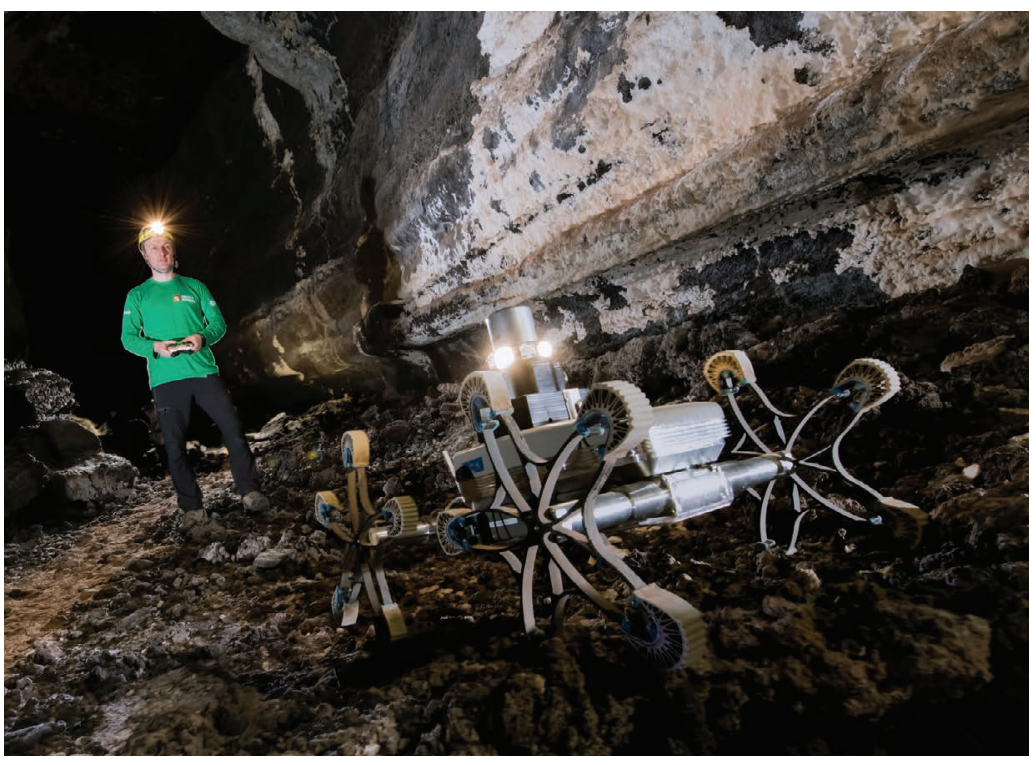

Prototype rovers are doing test runs in Spain's Canary Islands.
Matthias Sperl is testing another idea — growing artificial stone from regolith. In Sperl's lab, a beam of intense light, concentrated on a coin-sized patch, fuses together fizzing sheets of powder at a searing $1,100^{\circ} \mathrm{C}$. Over time, these layers add up to create dark grey, grainy bricks, as in a $3 \mathrm{D}$ printing process. On the Moon, sunlight could be concentrated to do the same thing, says Sperl, whose project is part of RegoLight, a $€ 1$-million collaboration between the DLR, Belgian aerospace company SAS and architecture and engineering firms. The sheets do not bond together perfectly, but the bricks are already around one-fifth as strong as concrete and comparable to plaster, says Sperl. Architecture firms Bollinger Grohmann Schneider and Liquifer Systems Group, both in Vienna, showed in April that by interlocking the bricks into arches and domes, they could create robust structures. Sperl says these are solid enough to survive Moon quakes and bear the weight of more gravel piled on for protection. Currently, the process takes around 5 hours to make a single brick - but channelling more sunlight could speed it up, he says. Scientists elsewhere are exploring making shelters by searing regolith together in microwave ovens, or binding it together with materials brought from Earth, such as polymers. with hydrogen to make water. A field test in Hawaii in 2010 on simulated lunar regolith demonstrated that the process was feasible - although working in low gravity and a vacuum is untested. "Essentially it's a proven technology and would be ready to go within a few years," says Mueller.

Researchers hope to improve the process further to cut down on what needs to be brought from Earth. At the Polytechnic of Milan in Italy, a group led by aerospace engineer Michèle Lavagna is developing a prototype that works at lower temperatures and recycles all the inputs - in this case, methane and hydrogen - so that soil is the only consumable. Currently, one device might take decades to generate enough water to power a single Apollo-style lander back into orbit. But Lavagna says that on the Moon, multiple reactors could work in parallel. With around $€ 600,000$ (US\$692,000) of ESA funding, her team is now working on a demonstrator plant that would be small enough to fly on a mission.

\section{FINDING SHELTER}

If it turns out that water can't be harvested for profit, an outpost based around scientific experiments will still develop, argues Maurer. "Without a commercial perspective, it simply will take much longer to materialize," he says. "We might end up in a situation similar to research in Antarctica - driven mainly by pure scientific interest."

Researchers are excited about the experiments that a return to the Moon could yield, says Robin Canup, a planetary scientist at the Southwest Research Institute in Boulder, Colorado. Sampling the Moon's ancient craters could reveal how the Moon-Earth system formed, when the early Solar System was in a state of flux and asteroids pummelled the satellite. Researchers would also like to study the Moon's water cycle and its seismology — and to install a radio-telescope shielded from Earth interference, which could study radiation from the early Universe.

Unlike in Antarctica, however, lunar residents need to be sheltered from the charged particles of radiation and tiny meteorites that rain down from space - because the Moon has next to no protective atmosphere or magnetic field. The first flat-pack shelters are likely to be brought from Earth, but would need to be covered with metres of sand or regolith, Maurer says. One solution is natural: to exploit cliffs, canyons, caves and lava tubes - tunnels caused by ancient volcanic activity — to protect living quarters. Last year, scientists reanalysing radar data from the Japanese space agency's SELENE orbiter and density measurements from NASA's GRAIL mission found a candidate tunnel that apparently runs for kilometres, beneath the Marius Hills on the Moon's near side. On Earth, researchers have already practised commanding rovers to drive in lava tubes in Lanzarote, in Spain's Canary Islands, to prepare for future lunar exploration.

A few hundred metres from LUNA, in a DLR laboratory in Cologne,

\section{KALE DIET}

Plant scientists have also spent a good deal of time thinking about the final ingredient needed in a self-supporting Moon base: food. As part of a closed ecosystem, plants would recycle organic waste and turn carbon dioxide into oxygen to breathe. In May, Chinese state media reported that volunteers finished a record 370-day stay inside such an ecosystem, a simulated base known as Lunar Palace 1, in which they grew crops and raised mealworms for protein.

Astronauts on the International Space Station (ISS) already eat spacegrown lettuce and other leafy greens. A NASA programme run from the Kennedy Space Center, known as Veggie, has helped to select crops that grow well in confined spaces and are packed with the nutrients that degrade most in storage - vitamins $\mathrm{C} 1, \mathrm{~K}$ and potassium. Kale is a winner. "It's a powerhouse that hits everything," says Veggie project manager Trent Smith.

On the Moon, astronauts would grow plants in water under white and red LEDs which they can tweak to alter the mineral and vitamin composition of the plant. Next year, ISS tests will examine how the composition of tomatoes changes depending on the light. More studies will be needed to establish how best to grow crops in regolith's mixture of metals. "We'd like to know what it takes to build living soils out of what is essentially space dust," says Smith. If plants can grow in regolith, adds Veggie researcher Matthew Romeyn, "suddenly that means bringing small fruit trees, not just leafy greens."

"If humans can only stay for short periods of time because of hazards, and if they can't grow food locally, the programme will implode," Mueller says. Another barrier might be a legal one: the 1967 Outer Space Treaty, which all major space-faring nations have signed, states that no country can "appropriate" any part of a celestial body. Most nations today accept that this does not rule out mining in space, says Dimitra Stefoudi, an expert in space law at the University of Leiden in the Netherlands. Since 2015, two countries, the United States and Luxembourg, have enacted national laws allowing space mining, to promote nascent companies. (Russia and Belgium are among countries which argue that mining needs a new international framework.) But the 1967 treaty also says that space activities should be for the benefit of all countries and humankind, so firms will still need to find ways to share know-how and the eventual gains of harvesting resources on the Moon, Stefoudi says.

Ultimately, says Mueller, setting up camp on the Moon is likely to be a desire checked not by technology, but by political will and economics. "If we can solve both of those, I absolutely believe that permanent inhabitation of the Moon will happen."

Elizabeth Gibney is a reporter for Nature in London. 